\title{
Tweeting @ Work: The use of social media in professional communication
}

\author{
Tanya Lewis \\ Live Science, 150 Fifth Ave, 9th Floor, New York, NY 10011, USA \\ Tel.: +1 212703 5868; E-mail: tlewis@livescience.com
}

\begin{abstract}
Social media has become almost a necessity in today's news environment. Science journalists use social media platforms like Twitter, Facebook and Google + to keep abreast of news, find story ideas, share their stories, cultivate authority and engage with readers.

Keywords: Social media, Twitter, Facebook, electronic communication, networking, crowdsourcing, audience engagement, tweeting, science journalism
\end{abstract}

\section{Motivation}

Today's media environment is fast and furious. Social media - forms of electronic communication that allow users to form online communities to share information, ideas, personal messages and other content - have in many cases supplanted traditional forms of electronic communication. There are many reasons for using social media in communicating science to specialists or members of the public: to be part of a global conversation in your field; to disseminate information to a target audience; to promote one's work or the work of one's institution; and to cultivate professional contacts, among others.

\section{Strategies}

There are many ways to use these online tools, but it can be helpful to conceptualize them as three modes: absorbing information, sharing information and engaging with others. Social media streams function increasingly as news aggregators - for example, many people heard the news of Steve Jobs' death over Twitter [1]. Individuals or organizations may use social media to share resources related to their own work or to the work of peers, which serves to cultivate authority in their field. Engaging with other individuals or organizations via social media enables one to find and strengthen professional connections, crowdsource ideas and gauge one's impact.

\section{Platforms}

Numerous social media platforms exist, but this abstract will focus on the microblogging site Twitter and the social network Facebook. 
Twitter currently has 255 million monthly active users (March, 2014) [2]. To manage the barrage of information, identifying key sources to follow is a critical, ongoing step, as is organizing one's Twitter feed with lists or social media dashboard applications (such as TweetDeck or Hootsuite). Twitter's strict character limit lends itself to the incorporation of links, which serve as a gateway to more indepth content. The use of hashtags can also draw an audience to a specific topic. But tweeting is not a one-way street - engagement with others (via @ mentions, direct messages or retweets) elevates the communication to a conversation.

Facebook has 1.28 billion monthly active users, more than 800 million of whom are active daily (March, 2014) [3]. In contrast to those on Twitter, personal accounts on Facebook cultivate a smaller, more personal following. However, content can still spread widely from user to user via shares. Facebook's image-friendly format can draw in followers and should be leveraged, when possible. As with Twitter, engaging with other users directly, e.g. by tagging users or posting on user/group pages, can broaden one's impact.

Other social media platforms exist, but regardless of which ones are used, a primary focus on a few platforms may be more effective than shallow participation in many.

\section{Conclusion}

Social media is a mode of communication that should not be ignored. Its many roles include: a source of news, a platform for global conversation, a vehicle for promoting or disseminating content, and a hub for professional networking. Using social media can be broadly classified into three modes: absorption of information, sharing of information and engagement with others. Twitter and Facebook represent two of the most widely used social media networks, which have similar uses but demand unique strategies.

\section{References}

[1] L. Katz, Twitter reacts with emotion to Steve Jobs' death, CNET, October 5, 2011, available at: http://www.cnet.com/ news/twitter-reacts-with-emotion-to-steve-jobs-death/, accessed June 12, 2014.

[2] Twitter First Quarter 2014 Results (quarter ending March 31), April 29, 2014, available at: https://investor.twitterinc.com/ releasedetail.cfm?releaseid $=843245$.

[3] Facebook First Quarter 2014 Results (quarter ending March 31), April 23, 2014, available at: http://investor.fb.com/ releasedetail.cfm?ReleaseID $=842071$. 